\title{
Seasonal Affective Disorder: An Overview of Assessment and Treatment Approaches
}

\author{
Sherri Melrose \\ Faculty of Health Disciplines, Athabasca University, Athabasca, AB, Canada T9S 3A3 \\ Correspondence should be addressed to Sherri Melrose; sherrim@athabascau.ca
}

Received 13 September 2015; Revised 1 November 2015; Accepted 10 November 2015

Academic Editor: Axel Steiger

Copyright (c) 2015 Sherri Melrose. This is an open access article distributed under the Creative Commons Attribution License, which permits unrestricted use, distribution, and reproduction in any medium, provided the original work is properly cited.

\begin{abstract}
Seasonal affective disorder or SAD is a recurrent major depressive disorder with a seasonal pattern usually beginning in fall and continuing into winter months. A subsyndromal type of SAD, or S-SAD, is commonly known as "winter blues." Less often, SAD causes depression in the spring or early summer. Symptoms center on sad mood and low energy. Those most at risk are female, are younger, live far from the equator, and have family histories of depression, bipolar disorder, or SAD. Screening instruments include the Seasonal Pattern Assessment Questionnaire (SPAQ). Typical treatment includes antidepressant medications, light therapy, Vitamin D, and counselling. This paper provides an overview of SAD.
\end{abstract}

\section{Introduction}

As sunlight decreases during the short dark days of winter, many individuals struggle with seasonal affective disorder or SAD. As the acronym so aptly illustrates, those afflicted experience feelings of sadness and loss of energy, especially during December, January, and February, around the winter solstice, when the days are shortest. Existing research has focused on the key treatment approaches of antidepressant medication, light therapy, Vitamin D, and counselling. This paper presents an overview of SAD by explaining the disorder and commenting on treatment approaches.

\section{An Explanation of Seasonal Affective Disorder (SAD)}

2.1. What Is SAD? Seasonal affective disorder or SAD is not considered a unique diagnostic entity. Rather, it is a type of recurring major depression with a seasonal pattern. According to the Diagnostic and Statistical Manual of Mental Disorders DSM-5 [1], criteria for depression with a seasonal pattern include having depression that begins and ends during a specific season every year (with full remittance during other seasons) for at least two years and having more seasons of depression than seasons without depression over a lifetime. Seasonal pattern disorders occur most frequently in winter although they can also occur in summer.

People with seasonal affective disorder have difficulty regulating the neurotransmitter serotonin, a neurotransmitter believed to be responsible for balancing mood [2]. In one study, people with SAD had 5\% more SERT, a protein that assists with serotonin transport, in the winter months than in summer [2]. SERT transports serotonin from the synaptic cleft to the presynaptic neuron, so higher SERT levels lead to lower serotonin activity, thus causing depression [2]. Throughout the summer, sunlight generally keeps SERT levels naturally low [2]. But as sunlight diminishes in the fall, a corresponding decrease in serotonin activity also occurs.

People with SAD may also have difficulty with overproduction of melatonin [3]. Melatonin is a hormone produced by the pineal gland that responds to darkness by causing sleepiness [4]. As winter days become darker, melatonin production increases and, in response, those with SAD feel sleepy and lethargic [5]. Although melatonin likely plays a role in impacting the symptoms of SAD, it cannot by itself account for these phenomena [6].

The combination of decreased serotonin and increased melatonin impacts circadian rhythms. Circadian rhythms or the body's internal 24-hour "clock" are synchronized to respond to the rhythmic light-dark changes that occur daily and throughout each of the seasons. For people with SAD, 
the circadian signal that indicates a seasonal change in day length has been found to be timed differently, thus making it more difficult for their bodies to adjust [7-9].

Further, with less outdoor exposure to sunlight on the skin in winter, people with SAD may produce less Vitamin $\mathrm{D}[10,11]$. As Vitamin D is believed to play a role in serotonin activity, Vitamin D deficiency and insufficiency have been associated with clinically significant depressive symptoms $[12,13]$. Causal links between serotonin, melatonin, circadian rhythms, Vitamin D, and SAD have not yet been confirmed. However, associations among these key factors are present and are continuing to be researched.

2.1.1. Symptoms. Symptoms of winter seasonal pattern disorders center on sad mood and low energy [14-18]. Information for the lay public identify that people with SAD can feel sad, irritable, and may cry frequently; and they are tired and lethargic, have difficulty concentrating, sleep more than normal, lack energy, decrease their activity levels, withdraw from social situations, crave carbohydrates and sugars, and tend to gain weight due to overeating $[5,19-21]$.

Conversely, in addition to irritability, symptoms of the less frequently occurring summer seasonal pattern disorder center on poor appetite with associated weight loss, insomnia, agitation, restlessness, anxiety, and even episodes of violent behavior $[22,23]$. It is important to note that seasonal pattern disorders vary in severity. Some individuals may experience a milder form of SAD known as subsyndromal S-SAD [2426], or most commonly as "winter blues." However, others can be severely incapacitated and unable to function. In some instances, symptoms of SAD can be as severe as those experienced by in-patients with nonseasonal depression [27, 28]. Like all depressive disorders, thoughts of suicide may be present $[29,30]$. Health professionals must always implement suicide assessments with people they believe have or might have SAD.

2.1.2. History. Although low mood and low energy levels during the short dark days of winter may have always been an expected part of life for those living far from the equator, they were first identified as a treatable clinical condition during the 1980s [31-34]. When physician Norman Rosenthal moved to the United States from his native South Africa, he noticed that he felt much less productive in the winter but returned to normal as soon as spring arrived [35]. In his work at the National Institutes of Health, NIH, in the US, Rosenthal collaborated with Al Lewy, who was researching melatonin, and with Tom Wehr who was researching how light suppressed melatonin and impacted circadian rhythms. Together, they applied and disseminated their findings about how bright light could effectively treat patients with SAD [31]. The notion of SAD as a depressive condition warranting further study resonated with many who live in northern latitudes and is now a common and well-documented disorder [36].

2.1.3. Prevalence. Seasonal affective disorder occurs four times more often in women than in men and the age of onset is estimated to be between 18 and 30 years [35]. Those living farthest from the equator in northern latitudes are most susceptible [37]. For example, in the United States, $1 \%$ of those who live in Florida and 9\% who live in Alaska experience SAD [38]. In Canada $15 \%$ of the population experience winter blues and 2 to $6 \%$ experience SAD [39]. In the United Kingdom, $20 \%$ experience winter blues and $2 \%$ experience SAD $[40,41]$.

Pinpointing prevalence is difficult as the disorder may go unreported and consequently underdiagnosed [42]. SAD can cooccur with other depressive, bipolar, attention deficit, alcoholism, and eating disorders, making it difficult to diagnose [43]. As people with SAD may also have subtle decreases in thyroid function, their hypothyroidism can mask symptoms of SAD [44]. Given that SAD is a disorder women often experience and one that is triggered by limited exposure to sunlight, nurses and other health professionals who do shift work may be at particular risk [45].

2.2. Seasonal Pattern Assessment Questionnaire (SPAQ). Clearly a significant number of people are living with the debilitating effects of SAD and are not functioning to their full potential. By screening for SAD and S-SAD, particularly in familiar primary care settings where clients are accustomed to coming for treatment, health professionals can help identify those who are suffering [46].

The Seasonal Pattern Assessment Questionnaire (SPAQ) first developed by Rosenthal and colleagues in 1984 [47] continues to be widely used [31, 48, 49]. The SPAQ is a retrospective, self-administered tool that screens for the existence of SAD and S-SAD. It is freely available in the public domain and can be downloaded from http://www.guilford .com/add/forms/rosenthal2.pdf. No training is required to use the tool.

2.2.1. Scoring the SPAQ. Scoring the SPAQ is not straightforward and clinicians and researchers use the tool in different ways. Questions two and three provide particularly useful information in that they yield a specific number on the Global Seasonality Score or GSS [49-51]. This number or score can immediately communicate whether SAD or S-SAD is likely present and the degree of severity. As such, health professionals can use these two questions to add GSS to their client/patient assessments.

In question two, respondents rate their sleep length, social activity, mood, weight, appetite, and energy level on Likert scales scored from 0 to 4 . In question three, respondents rate the degree that seasonal changes are a "problem" (mild, moderate, marked, severe, or disabling).

A GSS of 11 or above and a problem rating of at least moderate are indicative of SAD. A GSS of 9 or 10 and a problem rating of at least mild are indicative of S-SAD.

2.2.2. Reliability, Validity, and Specificity. The SPAQ has been demonstrated to be reliable in that it measures consistently and to be valid in that it measures what it was designed to measure [49, 51-53]. However, it has been criticized for having low specificity, meaning that results may suggest people who do not have $\mathrm{SAD}$ will score as though they 
do [48]. This low specificity may misclassify people with nonseasonal depressions. This misclassification could in turn indicate misleadingly high estimates of prevalence $[42,54]$.

\section{Treatment Approaches}

Treatment approaches typically include combinations of antidepressant medication, light therapy, Vitamin D, and counselling. The next section provides a brief outline of these.

3.1. Antidepressant Medications. SAD, like other depressions, is believed to be associated with a dysfunction in brain serotonin activity. Therefore, second generation antidepressants (SGAs), such as the Selective Serotonin Reuptake Inhibitors (SSRIs), particularly fluoxetine (Prozac), have emerged as promising antidepressant medication treatments [55-57]. In the seminal Canadian study comparing the effectiveness of fluoxetine and light therapy in SAD (Can-Sad), fluoxetine was found to be as effective and as well-tolerated as light therapy and it was more cost-effective [58].

Bupropion (Wellbutrin), another SGA SSRI, has also been widely promoted as an effective medication for treating SAD [59-61]. In the northern US and Canada, one study revealed that beginning bupropion XL 150-300 mg daily early in the season while people were still well did prevent recurrence of seasonal depressive episodes [62].

With any medication treatment, it is important to draw attention to the issue of adverse effects. A Cochrane review of second generation antidepressants (SGAs) and SAD emphasized that insufficient evidence exists to come to any overall conclusions on the use of SGAs for SAD; and the authors noted that up to $27 \%$ of participants treated with SGAs for SAD withdrew from the studies early due to adverse effects [63]. Therefore, although antidepressant medication is a viable and often convenient treatment for SAD, especially for those whose symptoms are incapacitating, other options should also be considered.

3.2. Light Therapy. Knowing the difference decreased daylight can make in triggering SAD and S-SAD, approaches seeking to replace the diminished sunshine using bright artificial light, particularly in the morning, have consistently showed promise [31, 33, 43, 58, 64-67]. Light therapy is also referred to as Bright Light Therapy (BLT) or phototherapy.

Light boxes can be purchased that emit full spectrum light similar in composition to sunlight. Symptoms of SAD and SSAD may be relieved by sitting in front of a light box first thing in the morning, from the early fall until spring [68]. In the Scandinavian countries, light rooms, where light is indirect and evenly distributed, are available [66]. Typically light boxes filter out ultraviolet rays and require 20-60 minutes of exposure to 10,000 lux of cool-white fluorescent light daily during fall and winter [67]. This is about 20 times as great as ordinary indoor lighting [38].

Adverse effects of light therapy are usually less severe than those associated with antidepressants. They include eyestrain, increased risk of age-related macular degeneration, headaches, irritability, and difficulty sleeping [5]. Ocular changes and abnormalities are not associated with light therapy [69]. Light therapy should not be used in conjunction with photosensitizing medications such as lithium, melatonin, phenothiazine antipsychotics, and certain antibiotics [69]. In some cases, hypomania and suicidal ideation may occur, especially during the first few days of treatment [70]. Light therapy use should be monitored by a health professional [71].

3.3. Vitamin D. A systematic review and meta-analysis concluded that low levels of Vitamin D are associated with depression [10]. Vitamin D concentration is assessed by serum 25-hydroxyvitamin D (25-OH D) levels: with optimal levels at $30 \mathrm{nq} / \mathrm{mL}$; insufficient levels at less than $30 \mathrm{ng} / \mathrm{mL}$; deficient levels at less than $20 \mathrm{ng} / \mathrm{mL}$; and intoxication levels at greater than $150 \mathrm{nq} / \mathrm{mL}$ [72]. Low levels of Vitamin D are usually due to insufficient dietary intake or lifestyle issues such as little outdoor exposure to sunshine [11]. During the winter months of November through February, those living about 33 degrees north or 30 degrees south of the equator are not able to synthesize Vitamin D [73].

Many people with SAD and S-SAD have insufficient or deficient levels of Vitamin D, and although no further studies have confirmed the findings, research investigating this association suggests that taking 100,000 IU daily may improve their symptoms [74, 75]. Taking Vitamin D before winter darkness sets in may help prevent symptoms of depression [12]. Adverse reactions or intoxication is rare but could occur from doses of more than 50,000 IU per day [72].

3.4. Counselling. Counselling approaches can provide help and support to people with SAD. In one study, six weeks of Cognitive Behavioral Therapy (CBT) provided in group format during two 90-minute sessions per week was as effective as 30 minutes of 10,000 lux of cool-white fluorescent light each morning [76]. An overarching goal of CBT is to break down problems that seem overwhelming and negative patterns by changing the way people think about them [5].

Other forms of counselling for SAD and S-SAD integrate elements of CBT by providing new ways of thinking about sad mood and low energy. When depressive symptoms are not severe, programs that help people improve their diet by limiting starches and sugars; increase their exercise; manage their stress; avoid social withdrawal; and spend more time outdoors are all recommended [5].

On his website, Norman Rosenthal encourages selfcounselling by finding ways to reduce the stress that inevitably accompanies the incapacitating symptoms of SAD. $\mathrm{He}$ found that Transcendental Meditation (TM), other forms of mindfulness, yoga, walking, and exercise that is personally enjoyable were beneficial [35]. Rosenthal advocates a diet high in proteins, vegetables, unprocessed foods, and complex carbohydrates. He also suggests planning winter trips to sunny locales before winter sets in and people lack the motivation to do so [35].

As the preceding sections explained, SAD is a disorder precipitated by lack of needed exposure to sunlight. Further, 
most SAD treatment approaches, the exception being antidepressant medications and counselling, are based on increasing people's exposure to bright light. Health professionals can play a critical role in supporting those who live with SAD by seeking to understand the condition more deeply, to integrate assessment tools such as SPAQ into their practice, and to become aware of current evidence-based treatment approaches.

\section{Conclusion}

In summary, this paper provided an overview of SAD and S-SAD or the "winter blues," explaining what the disorder is in relation to DSM-5 criteria, symptoms, history, and prevalence. People with SAD experience sad moods and low energy to the extent that they are not able to function. Those who live in northern latitudes are most at risk. The self-reported Global Functioning Scores on the Seasonal Pattern Assessment Questionnaire (SPAQ) can immediately communicate people's views about the severity of their illness.

Sunlight plays a critical role in the decreased serotonin activity, increased melatonin production, disrupted circadian rhythms, and low levels of Vitamin D associated with symptoms of SAD. Antidepressant medications offer some relief. However, light therapy, Vitamin D supplements, and counselling approaches are also emerging as effective treatments. This paper calls for health professionals to integrate SAD assessments and treatments into their practice, both with themselves and with those they care about and for.

\section{Conflict of Interests}

The author declares that there is no conflict of interests regarding the publication of this paper.

\section{References}

[1] American Psychiatric Association, Diagnostic and Statistical Manual of Mental Disorders, Fifth Edition (DSM-5), American Psychiatric Association, Arlington, Va, USA, 2013.

[2] B. McMahon, S. Andersen, M. Madsen et al., "P.1.i.037 Patients with seasonal affective disorder show seasonal fluctuations in their cerebral serotonin transporter binding," European Neuropsychopharmacology, vol. 24, supplement 2, p. S319, 2014.

[3] A. J. Lewy, B. J. Lefler, J. S. Emens, and V. K. Bauer, “The circadian basis of winter depression," Proceedings of the National Academy of Sciences of the United States of America, vol. 103, no. 19, pp. 7414-7419, 2006.

[4] A. L. Miller, "Epidemiology, etiology, and natural treatment of seasonal affective disorder," Alternative Medicine Review, vol. 10, no. 1, pp. 5-13, 2005.

[5] National Health Service, "Seasonal Affective DisorderSymptoms," United Kingdom Government website, http://www .nhs.uk/Conditions/Seasonal-affective-disorder/Pages/Symptoms .aspx.

[6] N. E. Rosenthal, D. A. Sack, F. M. Jacobsen et al., "Melatonin in seasonal affective disorder and phototherapy," Journal of Neural Transmission, supplement 21, pp. 257-267, 1986.

[7] G. Murray, E. E. Michalak, A. J. Levitt et al., "Therapeutic mechanism in seasonal affective disorder: do fluoxetine and light operate through advancing circadian phase?" Chronobiology International, vol. 22, no. 5, pp. 937-943, 2005.

[8] M. H. Teicher, C. A. Glod, E. Magnus et al., "Circadian restactivity disturbances in seasonal affective disorder," Archives of General Psychiatry, vol. 54, no. 2, pp. 124-130, 1997.

[9] T. A. Wehr, W. C. Duncan Jr., L. Sher et al., "A circadian signal of change of season in patients with seasonal affective disorder," Archives of General Psychiatry, vol. 58, no. 12, pp. 1108-1114, 2001.

[10] R. Anglin, Z. Samaan, S. Walter, and S. McDonald, "Vitamin $\mathrm{D}$ deficiency and depression in adults: systematic review and meta-analysis," British Journal of Psychiatry, vol. 202, no. 2, pp. 100-107, 2013.

[11] S. Penckofer, J. Kouba, M. Byrn, and C. E. Ferrans, "Vitamin $\mathrm{D}$ and depression: where is all the sunshine," Issues in Mental Health Nursing, vol. 31, no. 6, pp. 385-393, 2010.

[12] D. C. Kerr, D. T. Zava, W. T. Piper, S. R. Saturn, B. Frei, and A. F. Gombart, "Associations between vitamin D levels and depressive symptoms in healthy young adult women," Psychiatry Research, vol. 227, no. 1, pp. 46-51, 2015.

[13] M. Kjærgaard, K. Waterloo, C. E. A. Wang et al., "Effect of vitamin D supplement on depression scores in people with low levels of serum 25-hydroxyvitamin D: nested case-control study and randomised clinical trial," British Journal of Psychiatry, vol. 201, no. 5, pp. 360-368, 2012.

[14] S. K. Elmore, "Seasonal affective disorder, part II: phototherapy, an expanded role of the psychosocial nurse," Archives of Psychiatric Nursing, vol. 5, no. 6, pp. 365-372, 1991.

[15] J. M. Gill and L. N. Saligan, "Don't let SAD get you down this season," The Nurse Practitioner, vol. 33, no. 12, pp. 22-27, 2008.

[16] N. Hairon, "Helping patients to cope with seasonal affective disorder," Nursing Times, vol. 103, no. 46, pp. 25-26, 2007.

[17] B. K. Timby and N. E. Smith, "Seasonal affective disorder: shedding light on the wintertime blues. Promoting health and wellness," Nursing, vol. 35, no. 1, article 18, 2005.

[18] C. Zauderer and C. A. Ganzer, "Seasonal affective disorder: an overview," Mental Health Practice, vol. 18, no. 9, pp. 21-24, 2015.

[19] J. Blaszczak, "10 Things You Didn't Know About Seasonal Affective Disorder," [Fact sheet], Psych Central, 2013, http://psychcentral.com/lib/10-things-you-dont-know-about-seasonalaffective-disorder/.

[20] Mayo Clinic, "Seasonal affective disorder," [Fact sheet], Mayo Clinic, Rochester, Minn, USA, http://www.mayoclinic.org/ diseases-conditions/seasonal-affective-disorder/basics/symptoms/ con-20021047? $\mathrm{p}=1$.

[21] MedicineNet.com, What is Seasonal Affective Disorder SAD? [Fact sheet], MedicineNet, San Clemente, Calif, USA, http://www.medicinenet.com/seasonal_affective_disorder_sad/ article.htm.

[22] R. Dryden-Edwards, Seasonal Depression SAD, emedicinehealth, San Clemente, Calif, USA, 2015, http://www.emedicinehealth.com/seasonal_depression_sad/article_em.htm.

[23] D. Oren, "Update on seasonal affective disorder," Psychiatric Times, vol. 31, no. 2, pp. 1-8, 2014.

[24] Canadian Mental Health Association, Seasonal Affective Disorder [Fact Sheet], Canadian Mental Health Association, Ottawa, Canada, 2009, http://northwestvancouver.cmha.bc.ca/ get-informed/mental-health-information/sad\#A.

[25] S. Kasper, T. A. Wehr, J. J. Bartko, P. A. Gaist, and N. E. Rosenthal, "Epidemiological findings of seasonal changes in mood and behavior. A telephone survey of Montgomery County, Maryland," Archives of General Psychiatry, vol. 46, no. 9, pp. 823-833, 1989. 
[26] R. W. Lam, E. M. Tam, L. N. Yatham, I.-S. Shiah, and A. P. Zis, "Seasonal depression: the dual vulnerability hypothesis revisited," Journal of Affective Disorders, vol. 63, no. 1-3, pp. 123132, 2001.

[27] T. Dalgleish, A.-M. J. Golden, J. Yiend, and B. D. Dunn, "Differential predictions about future negative events in seasonal and non-seasonal depression," Psychological Medicine, vol. 40, no. 3 , pp. 459-465, 2010.

[28] N. E. Rosenthal, "Issues for DSM-V: seasonal affective disorder and seasonality," American Journal of Psychiatry, vol. 166, no. 8, pp. 852-853, 2009.

[29] R. Lam and A. Levitt, Clinical Guidelines for the Treatment of Seasonal Affective Disorder, Clinical \& Academic Publishing, Vancouver, Canada, 1990.

[30] N. Praschak-Rieder, A. Neumeister, B. Hesselmann, M. Willeit, C. Barnas, and S. Kasper, "Suicidal tendencies as a complication of light therapy for seasonal affective disorder: a report of three cases," Journal of Clinical Psychiatry, vol. 58, no. 9, pp. 389-392, 1997.

[31] C. Overy and E. Tansey, The Recent History of Seasonal Affective Disorder (SAD), vol. 51 of Wellcome Witnesses to Contemporary Medicine, University of London, London, UK, 2014, http://www.histmodbiomed.org/sites/default/files/W51_ LoRes.pdf.

[32] N. Rosenthal, Winter Blues Seasonal Affective Disorder: What It Is and How to Overcome It, Guilford Press, London, UK, 1998.

[33] N. E. Rosenthal, D. A. Sack, J. C. Gillin et al., "Seasonal affective disorder. A description of the syndrome and preliminary findings with light therapy," Archives of General Psychiatry, vol. 41, no. 1, pp. 72-80, 1984.

[34] N. E. Rosenthal and T. A. Wehr, "Seasonal affective disorders," Psychiatric Annals, vol. 17, no. 10, pp. 670-674, 1987.

[35] N. Rosenthal, "What is seasonal affective disorder? Answers from the doctor who first described the condition," Dr. Rosenthal's personal website, http://www.normanrosenthal .com/seasonal-affective-disorder/.

[36] A. Magnusson, "An overview of epidemiological studies on seasonal affective disorder," Acta Psychiatrica Scandinavica, vol. 101, no. 3, pp. 176-184, 2000.

[37] L. N. Rosen, S. D. Targum, M. Terman et al., "Prevalence of seasonal affective disorder at four latitudes," Psychiatry Research, vol. 31, no. 2, pp. 131-144, 1990.

[38] S. Horowitz, "Shedding light on seasonal affective disorder," Alternative and Complementary Therapies, vol. 14, no. 6, pp. 282-287, 2008.

[39] Mood Disorders Association of Ontario, "How prevalent is SAD?" Mood Disorders of Ontario, Toronto, Canada, https:// www.mooddisorders.ca/faq/seasonal-affective-disorder-sad.

[40] Seasonal Affective Disorder Association, About SAD [Fact sheet], Seasonal Affective Disorder Association (SADA), Wallingford, UK, http://www.sada.org.uk/what_is_sad_2.php.

[41] Mindyourmind, "Seasonal Affective Disorder [Fact Sheet]," Mindyourmind, http://mindyourmind.ca/illnesses/seasonalaffective-disorder.

[42] C. Thompson, S. Thompson, and R. Smith, "Prevalence of seasonal affective disorder in primary care; a comparison of the seasonal health questionnaire and the seasonal pattern assessment questionnaire," Journal of Affective Disorders, vol. 78, no. 3, pp. 219-226, 2004.

[43] S. J. Lurie, B. Gawinski, D. Pierce, and S. J. Rousseau, "Seasonal affective disorder," American Family Physician, vol. 74, no. 9, pp. 1521-1524, 2006.
[44] L. Sher, N. E. Rosenthal, and T. A. Wehr, "Free thyroxine and thyroid-stimulating hormone levels in patients with seasonal affective disorder and matched controls," Journal of Affective Disorders, vol. 56, no. 2-3, pp. 195-199, 1999.

[45] G. D. Morin, "Seasonal affective disorder, the depression of winter: a literature review and description from a nursing perspective," Archives of Psychiatric Nursing, vol. 4, no. 3, pp. 182-187, 1990.

[46] A. Mcleod and C. Clemency, " 8 do's \& don'ts of mental health: integrating behavioral health treatment into primary care practice," Advance Healthcare Network for NPs \& PAs, vol. 2, no. 6, pp. 35-36, 2011, http://nurse-practitioners-and-physicianassistants.advanceweb.com/Features/Articles/8-Dos-Donts-ofMental-Health.aspx.

[47] N. Rosenthal, G. Bradt, and T. Wehr, Seasonal Pattern Assessment Questionnaire (SPAQ), National Institute of Mental Health, Bethesda, Md, USA, 1984.

[48] G. Brancaleoni and V. Hansen, "Classification of recurrent depression with seasonal pattern: a comparison between two diagnostic instruments," European Psychiatry, vol. 28, supplement 1, p. 610, 2011.

[49] P. P. A. Mersch, N. C. Vastenburg, Y. Meesters et al., “The reliability and validity of the seasonal pattern assessment questionnaire: a comparison between patient groups," Journal of Affective Disorders, vol. 80, no. 2-3, pp. 209-219, 2004.

[50] R. Lam, Notes on How to Use SPAQ and HAM-D [Fact Sheet], University of British Columbia, SAD Information, Vancouver, Canada, 2009.

[51] H.-C. Steinhausen, R. Gundelfinger, and C. Winkler Metzke, "Prevalence of self-reported seasonal affective disorders and the validity of the seasonal pattern assessment questionnaire in young adults: Findings from a Swiss community study," Journal of Affective Disorders, vol. 115, no. 3, pp. 347-354, 2009.

[52] A. Magnusson, S. Friis, and S. Opjordsmoen, "Internal consistency of the seasonal pattern assessment questionnaire (SPAQ)," Journal of Affective Disorders, vol. 42, no. 2-3, pp. 113-116, 1997.

[53] N. M. Øyane, R. Ursin, S. Pallesen, F. Holsten, and B. Bjorvatn, "Increased health risk in subjects with high self-reported seasonality," PLoS ONE, vol. 5, no. 3, Article ID e9498, 2010.

[54] C. Thompson and A. Cowan, "The Seasonal Health Questionnaire: a preliminary validation of a new instrument to screen for seasonal affective disorder," Journal of Affective Disorders, vol. 64, no. 1, pp. 89-98, 2001.

[55] R. W. Lam, A. J. Levitt, R. D. Levitan et al., "The can-SAD study: a randomized controlled trial of the effectiveness of light therapy and fluoxetine in patients with winter seasonal affective disorder," American Journal of Psychiatry, vol. 163, no. 5, pp. 805-812, 2006.

[56] L. Morgan, G. Gartlehner, B. Nussbaumer et al., "Efficacy and harms of second-generation antidepressants for the prevention of seasonal affective disorder: a systematic review," European Psychiatry, vol. 30, supplement 1, 808 pages, 2015.

[57] N. Praschak-Rieder and M. Willeit, "Treatment of seasonal affective disorders," Dialogues in Clinical Neuroscience, vol. 5, no. 4, pp. 389-398, 2003.

[58] A. Cheung, C. Dewa, E. E. Michalak et al., "Direct health care costs of treating seasonal affective disorder: a comparison of light therapy and fluoxetine," Depression Research and Treatment, vol. 2012, Article ID 628434, 5 pages, 2012.

[59] S. C. Dilsaver, A. B. Qamar, and V. J. Del Medico, "The efficacy of bupropion in winter depression: results of an open trial," The Journal of Clinical Psychiatry, vol. 53, no. 7, pp. 252-255, 1992. 
[60] British Columbia Drug and Poison Information Centre, Seasonal Affective Disorder SAD [Fact sheet], British Columbia Drug and Poison Centre, Victoria, Canada, 2013, http://www .dpic.org/article/professional/seasonal-affective-disorder-sad.

[61] Mayo Clinic, Bupropian, Fact sheet, Mayo Clinic, Rochester, Minn, USA, http://www.mayoclinic.org/drugs-supplements/ bupropion-oral-route/description/drg-20062478.

[62] J. G. Modell, N. E. Rosenthal, A. E. Harriett et al., "Seasonal affective disorder and its prevention by anticipatory treatment with bupropion XL," Biological Psychiatry, vol. 58, no. 8, pp. 658667, 2005.

[63] K. Thaler, M. Delivuk, A. Chapman, B. N. Gaynes, A. Kaminski, and G. Gartlehner, "Second-generation antidepressants for seasonal affective disorder," Cochrane Database of Systematic Reviews, vol. 7, no. 12, Article ID CD008591, 2011.

[64] J. M. Eagles, "Light therapy and seasonal affective disorder," Psychiatry, vol. 8, no. 4, pp. 125-129, 2009.

[65] T. Partonen and J. Lönnqvist, "Seasonal affective disorder," The Lancet, vol. 352, no. 9137, pp. 1369-1374, 1998.

[66] C. Rastad, J. Ulfberg, and P. Lindberg, "Improvement in fatigue, sleepiness, and health-related quality of life with bright light treatment in persons with seasonal affective disorder and Subsyndromal SAD," Depression Research and Treatment, vol. 2011, Article ID 543906, 10 pages, 2011.

[67] G. Virk, G. Reeves, N. E. Rosenthal, L. Sher, and T. T. Postolache, "Short exposure to light treatment improves depression scores in patients with seasonal affective disorder: a brief report," International Journal on Disability and Human Development, vol. 8, no. 3, pp. 283-286, 2009.

[68] A. Weil, Light Therapy. [Fact Sheet], Andrew Weil MD, Tempe, Ariz, USA, 2015, http://www.drweil.com/drw/u/ART03222/ Light-Therapy.html.

[69] P. F. Gallin, M. Terman, C. E. Reme, B. Rafferty, J. S. Terman, and R. M. Burde, "Ophthalmologic examination of patients with seasonal affective disorder, before and after bright light therapy," American Journal of Ophthalmology, vol. 119, no. 2, pp. 202-210, 1995.

[70] M. Terman and J. S. Terman, "Light therapy for seasonal and nonseasonal depression: efficacy, protocol, safety, and side effects," CNS Spectrums, vol. 10, no. 8, pp. 647-663, 2005.

[71] R. H. Howland, "Somatic therapies for seasonal affective disorder," Journal of Psychosocial Nursing and Mental Health Services, vol. 47, no. 1, pp. 17-20, 2009.

[72] M. F. Holick, "Vitamin D deficiency," The New England Journal of Medicine, vol. 357, no. 3, pp. 266-281, 2007.

[73] A. R. Webb, L. Kline, and M. F. Holick, "Influence of season and latitude on the cutaneous synthesis of vitamin $\mathrm{D}_{3}$ : exposure to winter sunlight in Boston and Edmonton will not promote vitamin $\mathrm{D}_{3}$ synthesis in human skin," The Journal of Clinical Endocrinology \& Metabolism, vol. 67, no. 2, pp. 373-378, 1988.

[74] F. M. Gloth III, W. Alam, and B. Hollis, "Vitamin D vs broad spectrum phototherapy in the treatment of seasonal affective disorder," Journal of Nutrition, Health and Aging, vol. 3, no. 1, pp. 5-7, 1999.

[75] A. E. Stewart, K. A. Roecklein, S. Tanner, and M. G. Kimlin, "Possible contributions of skin pigmentation and vitamin D in a polyfactorial model of seasonal affective disorder," Medical Hypotheses, vol. 83, no. 5, pp. 517-525, 2014.

[76] K. J. Rohan, J. N. Mahon, M. Evans et al., "Randomized trial of cognitive-behavioral therapy versus light therapy for seasonal affective disorder: acute outcomes," The American Journal of Psychiatry, vol. 172, no. 9, pp. 862-869, 2015. 


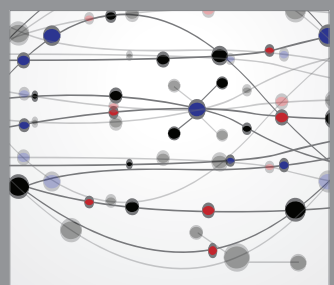

The Scientific World Journal
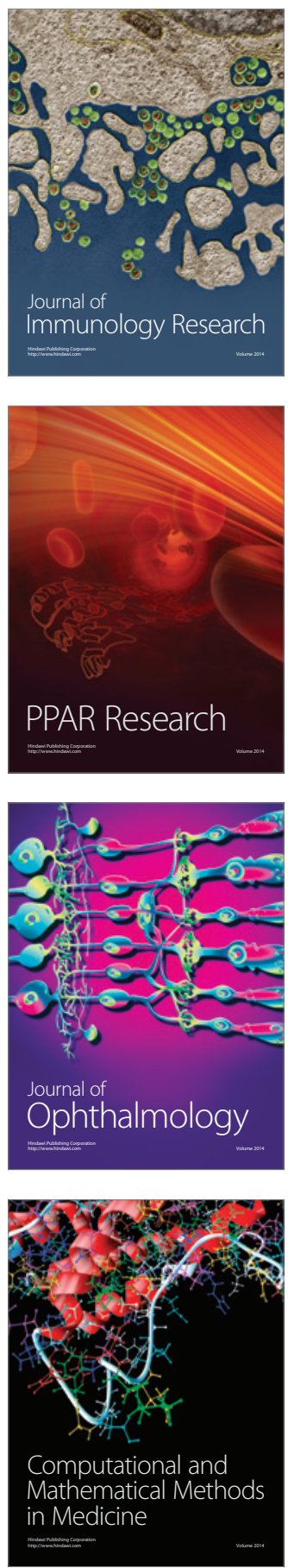

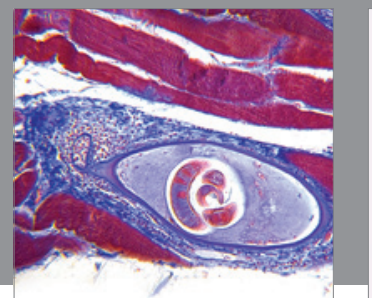

Gastroenterology

Research and Practice
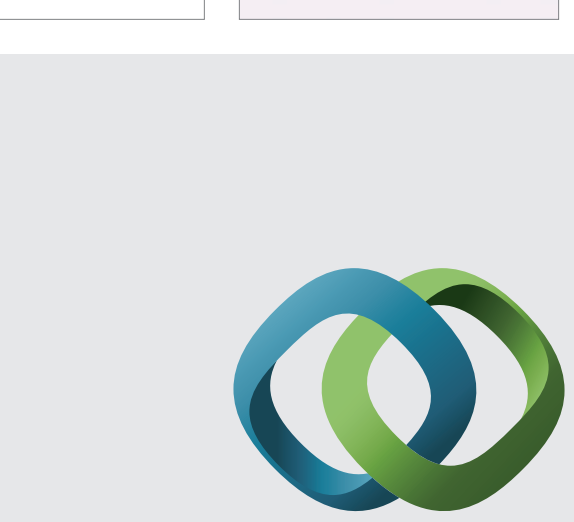

\section{Hindawi}

Submit your manuscripts at

http://www.hindawi.com
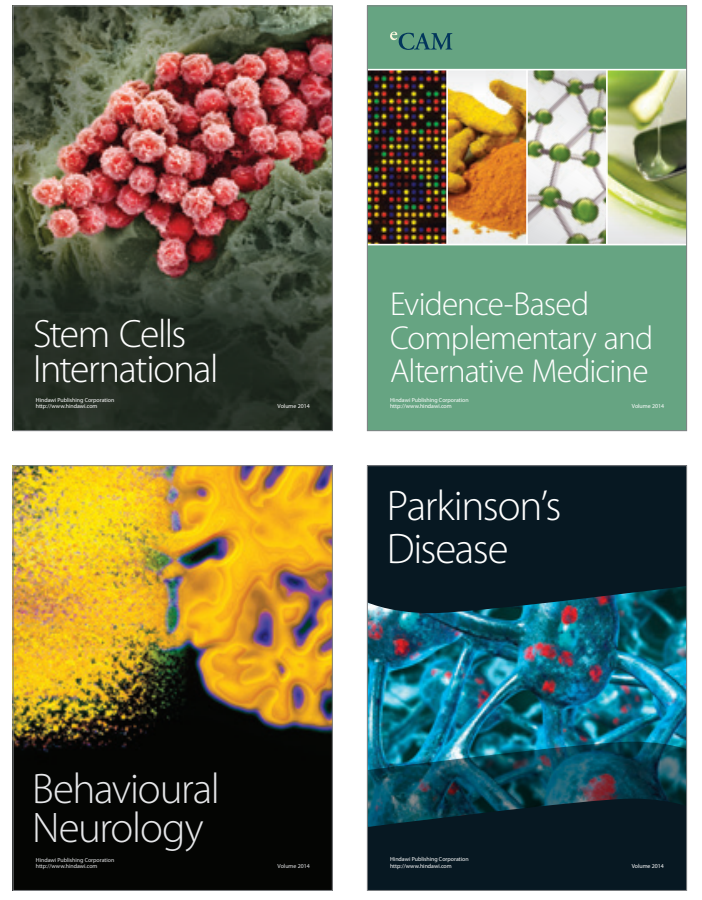
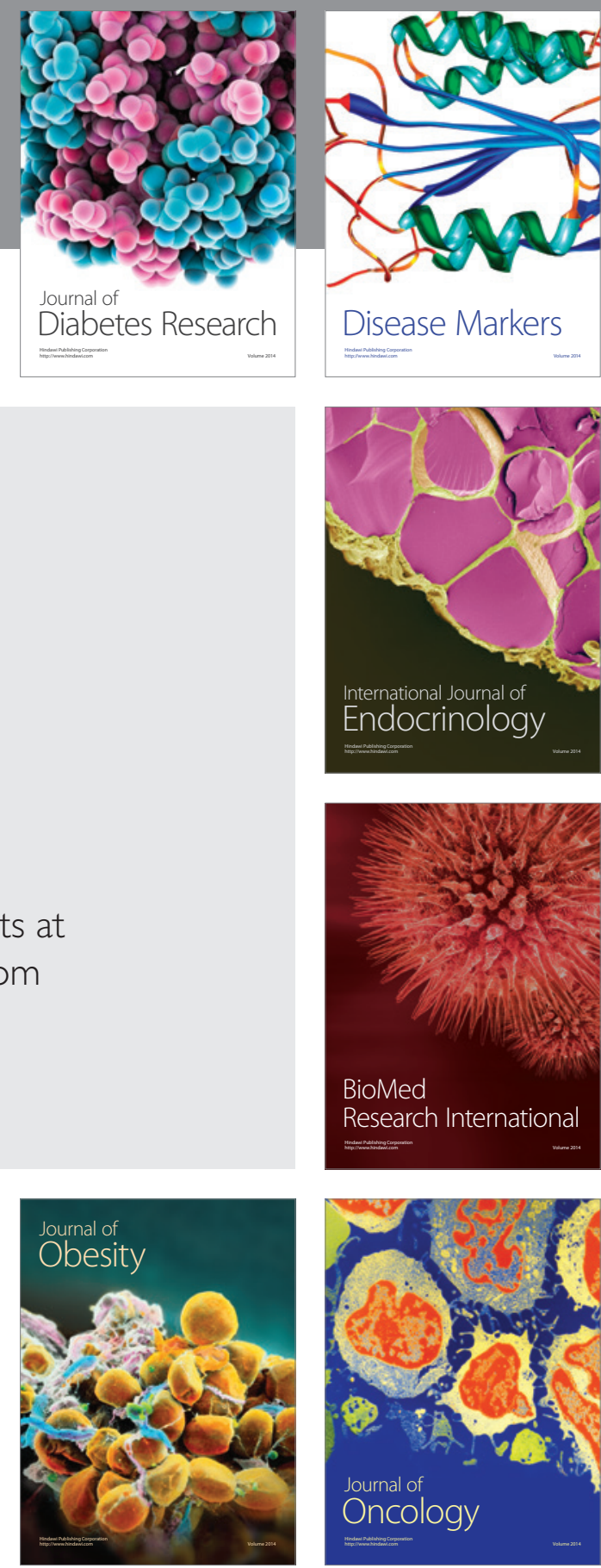

Disease Markers
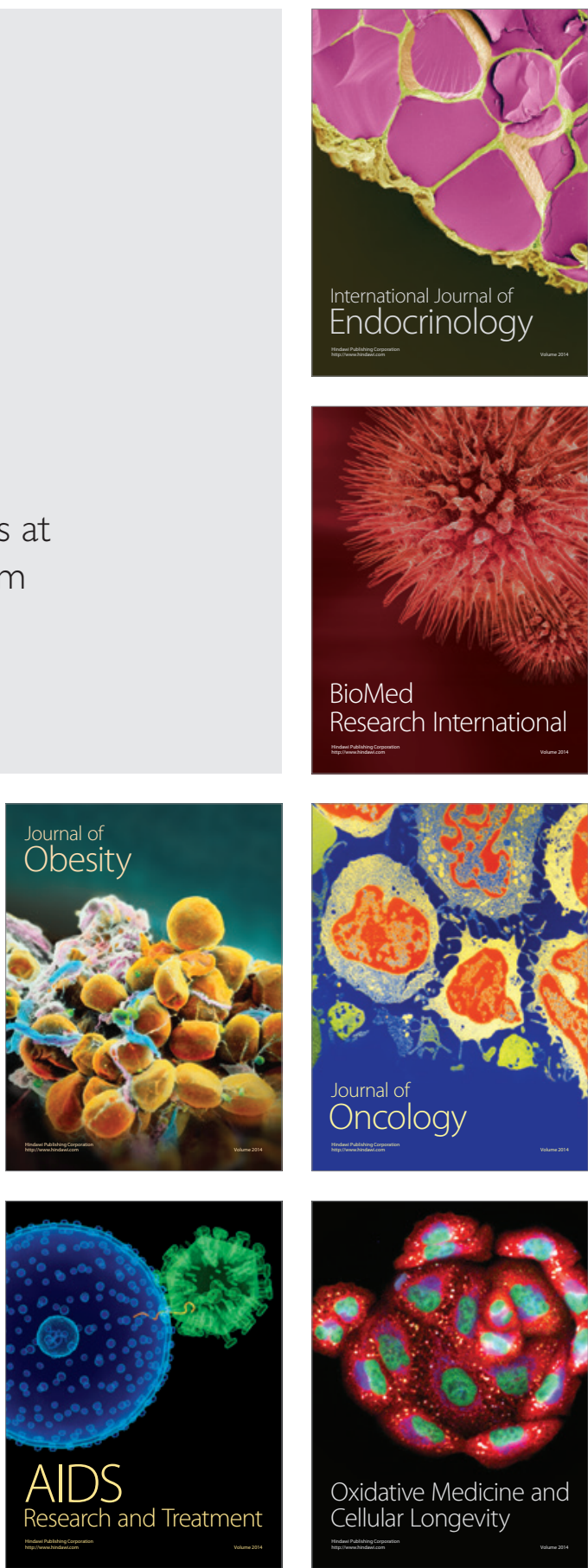